\title{
Diverse Women Faculty Experiences Using Identity and Relational Concepts to teach Cultural Competence
}

\section{Williams, LaShawn}

Behavioral Science Department, Utah Valley University, United States of America

\begin{abstract}
This article partially engages the qualitative sections of Williams' 2017 research study that aimed to explore faculty experiences using relational concepts to teach cultural competence. Multiple experiences were common to respondents from the results obtained at completion of the survey. Implications for social work education, faculty mentorship and support are discussed. It was concluded that there is an express need for early intervention on behalf of doctoral students being mentored for teaching appointments, the use of identity is a healthy and connecting touchstone in social work education classrooms and ongoing work is needed to challenge the work of deconstructing privilege in service of using professional and personal identity to connect content to effective knowledge transfer.
\end{abstract}

Keywords: Social Work; Diversity; Relational-Cultural Theory; Cultural Competence; Relational Teaching. 


\section{Introduction}

This article discusses some of the qualitative results from Williams' 2017 mixed-methods research project seeking to explore the experiences of social work faculty teaching cultural competence from a lens of relational cultural theory (RCT). Relational Cultural Theory "emphasizes health growth and courage, and points to a new understanding of human and individual strengths: strength in relationship, not strength in isolation" (Jordan \& Hartling, 2002, p. 51). Jordan and Hartling explain that "isolation is seen as the source of the most suffering, while the process of creating mutual empathy and mutual empowerment is seen as the route out of isolation" (Jordan \& Hartling, 2002, p. 51). Relational Cultural theory is an approach that emphasizes relationships, change, and growth. These things happen because of the ability to create and manage relational movement. (Williams, 2017)

Faculty were invited to share their teaching experiences related to specific RCT-based relational teaching concepts. Introduced by Edwards and Richards (2002), relational teaching is a pedagogy based in relational cultural theory. It describes the participation in growth-fostering relationships as a critical element in teaching students by focusing on three components that foster growth: mutual engagement, mutual empathy, and mutual empowerment. (Williams, 2017)

Faculty participation was sought in the Western region of the United States and extended to additional states along the country's borders. Respondents in the quantitative section were invited to participate in the qualitative section upon completion of the survey. There were initially 74 quantitative respondents. Of those respondents, 38 opted-in for future contact to complete the qualitative section. From the 38 interested in future contact, just 4 completed the qualitative portion of the study. All four respondents identified as women. (Williams, 2017)

\section{Qualitative Results and Interpretations}

This study sought experiences of social work faculty teaching diversity and cultural competence at schools accredited by the Council on Social Work Education (CSWE). The results of each question provided insight for additional research looking at the use of relationship in the classroom according to relational teaching principles. (Williams, 2017)

Social work faculty members' teaching experiences connected with relational cultural theory concepts outlined in relational teaching (Edwards \& Richards, 2002; Williams, 2017). Each relational teaching concept connected to current literature associated with social work faculty experiences in teaching social justice and intersectionality (Robinson, Cross-Denny, Lee, Werkmeister Rozas, \& Yamada, 2016), cultural competence (Saunders, Haskins, \& Vasquez, 2015), white privilege and identity development for faculty and 
students (Davis, Mirick, \& McQueen, 2015), as well as faculty reflection on their teaching experiences. The most common component in each relational teaching concept's cluster of themes was that of identity. Identity became a conduit of faculty connection in the classroom (Williams, 2017).

Identity was a conduit of connection between students and faculty because faculty highlighted their use of their own racial, ethnic, gender, and other identities to help students connect with their own identities. Faculty worked to create positive classroom cultures that allowed expression and risk, promoting a continuation of exploring racial and ethnic identity processes. (Williams, 2017) Faculty noted using various pedagogical approaches to teach cultural differences (Saunders, Haskins \& Vasquez, 2015) when they noted being impacted by student experiences which were shared in the classroom. This sharing created examples of the relational teaching concept of mutual empathy. Finally, identity was discussed as a conduit of connection when it exposed the support faculty provided students in their learning process through curricular adjustments that encouraged growth and contributed to the development of professional identity (Williams, 2017).

\section{Implications/Recommendations for Social Work Education}

Faculty who used their identities and named similarities were able to share examples with students. These examples legitimized and gave permission for faculty to teach about difference. While this provided some intellectual interaction, results showed that it did so with the presence of some emotional distance evidenced in responses (Williams, 2017). Some faculty who experienced having to use themselves as examples to connect in a negative way expressed frustrations. They stated that doing so without the support of colleagues or members in leadership was difficult. Others felt that they lacked experiential connections that mattered to their students (sometimes even with the support of colleagues and leadership) (Williams, 2017). Additionally, examples of the commitment to effective teaching of cultural competence sometimes contributed to "othering" processes (Diggles, 2014) used to teach cultural competence. A lack of awareness was demonstrated at times. A lack of motivation to self-reflect on the impact of their practices was evidenced in responses. Thus, a major implication for this study and the future of social work educators is the explicit use of self as a practitioner-in-progress. (Williams, 2017) Williams suggests a heavier usage of critical race theory (Diggles, 2014), intersectionality (Robinson et al. 2016), and de-centering privilege as techniques that will invite a deeper instructional authenticity of learning with and from one's students. Implications from this study recommend a refocus on the power of relationship and constructing student identities as allies (Gibson, 2014) in similar and different ways from instructors. Students can learn to 
take risks in safe environments by seeing faculty do the same, knowing that learning from mistakes is encouraged and part of the growth process.

The above information, however, is impossible without the support, guidance, and mentorship to help faculty go further than using their identity as a starting place to actively creating an ongoing and dynamic relationship with students-as-allies where all are encouraged to "go first" and supported in the leadership process of cultural learning. Although faculty successfully demonstrated an ability to support students in their explorations of cultural identity and cultural competence, literature speaks to the need for faculty to have similar support in their professional ranks as that provided to students in the classroom experience.

Mentoring of women faculty members in the academy is noted by Williams a natural extension of relational cultural theory concepts (2017). Five are specifically outlined by Hammer, Trepal, and Speedlin (2014), namely attending to power, focusing on mutuality, fostering authenticity, listening into voice, and building a sense of community and connection. Gammel and Rustein-Riley (2016) propose that mentoring begin at the doctoral level for women faculty. In this study, some respondents stated having, and appreciating, support from colleagues on campus as they engaged the work of diversity and difference in their classrooms. Other respondents in this study did not report such support. This is a significant need for faculty from historically marginalized populations. (Williams, 2017) The burden of teaching diversity concepts and introducing social justice components into curriculum is documented as being especially challenging for faculty of color (Edwards, Bryant \& Clark, 2008; Moule, 2005). Williams' implications from this study point towards further research of the faculty experience in specifically engaging resistance and disconnection in the classroom from the perspective of relational cultural theory's "creative work toward mutual empathy" 5-step approach (Comstock, Duffey, \& St. George, 2002). Williams states that this can be accomplished with the active support and ongoing development of mentoring networks (2017).

\section{Limitations of this Study}

The major limitation documented in this study was the sample size. It was too small to make any generalizations that could apply to the profession of social work education. In addition to the sample size, it was noted that both the the gender of participants who returned information for the qualitative portion of the study were women. As previously stated (Williams, 2017), there was no intent in this study to exclude people of any gender identity or expression from participation. 


\section{Summary}

In summary, this partial discussion of Williams' 2017 study demonstrates an ongoing need of support for and guidance in the experiences of women in academia who actively use the many intersections of their identity to help further the work of cultural competence. Further study of faculty experiences focusing on shame and entitlement when teaching diversity would be of benefit to learning how to support faculty who struggle and to mitigate the effects of faculty who may do harm due to the blind spots that can be created from equating training attendance with effective cultural competence. More research is needed about the inner journeys of faculty members to do the deconstructing work of their own privileges in order to give students active role models in the life-long process of anti-oppression knowledge transfer in social work education classes (Williams, 2017).

\section{References}

Avant, D. W., \& Bracy, W. (2015). Teaching Note-Using Problem-Based Learning to Illustrate the Concepts of Privilege and Oppression. Journal of Social Work Education, 51(3), 604-614.

Comstock, D., Duffey, T., \& St. George, H. (2002). The relational cultural model: A framework for group process. The Journal for Specialists in Group Work, 27(3), 254272. doi:10.1177/019339220207003002

Davis, A., Mirick, R., \& McQueen, B. (2015). Teaching from privilege: Reflections from white female instructors. Affilia: Journal Of Women \& Social Work, 30(3), 302-313. doi:10.1177/0886109914560742

Diggles, K. (2014). Addressing Racial Awareness and Color-Blindness in Higher Education. New Directions For Teaching \& Learning, 2014(140), 31-44. doi:10.1002/tl.2011

Edwards, J., Bryant, S., \& Clark, T. (2008). African American Female Social Work Educators in Predominantly White Schools of Social Work: Strategies for Thriving. Journal of African American Studies, 12(1), 37-49. doi:10.1007/s12111-007-9029-y

Edwards, J., \& Richards, A. (2002). Relational teaching: A view of relational teaching in social work education. Journal of Teaching in Social Work, 22(1/2), 33-48. doi:10.1300/J067v22n01_04

Gammel, J. A., \& Rutstein-Riley, A. (2016). A Relational Approach to Mentoring Women Doctoral Students. New Directions For Teaching \& Learning, 2016(147), 27. doi:10.1002/tl.20196

Gibson, P. A. (2014). Extending the Ally Model of Social Justice to Social Work Pedagogy. Journal of Teaching In Social Work, 34(2), 199-214. 
Hammer, T., Trepal, H., \& Speedlin, S. (2014). Five Relational Strategies for Mentoring Female Faculty. Adultspan Journal, 13(1), 4-14. doi:10.1002/j.2161-0029.2014.00022.x

Jordan, J. V., \& Hartling, L. M. (2002). New developments in relational-cultural theory. In M. Ballou \& L. S. Brown (Eds.), Rethinking mental health and disorder: Feminist perspectives (pp. 48-70). New York, NY: Guilford.

Moule, J. (2005). Implementing a Social Justice Perspective in Teacher Education: Invisible Burden for Faculty of Color. Teacher Education Quarterly, 32(4), 23-42

Robinson, M. A., Cross-Denny, B., Lee, K. K., Werkmeister Rozas, L. M., \& Yamada, A. (2016). Teaching Note-Teaching Intersectionality: Transforming Cultural Competence Content in Social Work Education. Journal of Social Work Education, 52(4), 509-517. doi:10.1080/10437797.2016.1198297

Saunders, J. A., Haskins, M., \& Vasquez, M. (2015). Cultural Competence: A Journey to an Elusive Goal. Journal Of Social Work Education, 51(1), 19-34.

Williams, L. C. (2017). Mind the disconnect: Social work faculty experiences with relational teaching and diversity content(Order No. 10284362). Available from ProQuest Dissertations \& Theses A\&I. (1954047998). Retrieved from https://search.proquest.com/docview/1954047998?accountid=14779 